DOI 10.37882/2223-2982.2020.06.34

\title{
ТЕРМИНОЛОГИЧЕСКОЕ ПОЛЕ «ПЧЕЛОВОДСТВО» В ЕГО СИСТЕМНЫХ СВЯЗЯХ
}

\section{THE TERMINOLOGICAL FIELD "BEEKEEPING» IN ITS SYSTEM CONNECTIONS}

\section{Titova}

Summary: The article presents the language of beekeeping in the Altai, the appearance of which formed a new layer of professional vocabulary for the region. This fragment especially clearly illustrates the principles of dividing this lexical layer into microgroups in accordance with the stages of technological production of bee products, and also demonstrates the paradigmatic relationships of the presented word meanings. The vocabulary of beekeeping is mentioned in modern research, but it is not collected purposefully in other regions. In Altai, the unique vocabulary of beekeeping is collected according to a specially developed programme. This article analyzes the professional vocabulary of Altai beekeepers in the aspect of the relationship between language and culture, and also examines the composition of the vocabulary of beekeeping in terms of system connections.

Keywords: language and culture, beekeepers' lexis, paradigmatic connections, terminology system connections.
$A^{\prime}$ лтайский край на протяжении долгого времени остается одним из самых пчеловодных районов России. Процесс распространения данного промысла на Алтае был длительным и многоэтапным, что обеспечило многоуровневый массив терминологической лексики, описывающий все этапы технологического процесса получения продуктов пчеловодства. Возможность изучения такой лексики при делении на группы очевидны исследуется давно. Так, М.М. Покровский отметил, что «...слова и их значения живут не отдельной друг от друга жизнью, но соединяются (в нашей душе), независимо от нашего сознания, в различные группы, причем основанием для группировки служит сходство или прямая противоположность по основному значению» [1, с. 82]. Для выделения критериев разграничения тематических полей (групп) было необходимо соотнести каждое слово из анализируемого материала с конкретным этапом производства и лексико-семантического поля (группы). Лексикосемантическая группа является частью, входящей в состав тематической группы. Таким образом, данная тематическая группа представляет собой классификацию лексических единиц с опорой на деление самих явлений и предметов, для обозначения которых и служит данная лексика. Например, «Названия ульев»,
Титова Марина Владимировна

К.филол.н., дочент, ФГБОУ «Алтайский государственный

университет»

titova-marina80@rambler.ru

Аннотация: В статье представлен язык пчеловодства на Алтае, появление которого сформировало новый для региона пласт профессиональной лексики. Данный фрагмент особенно ярко иллюстрирует принципы деления данного лексического пласта на микрогруппы в соответствии с этапами технологического производства продуктов пчеловодства, а также демонстрирует парадигматические связи представленных значений слов. Лексика пчеловодства упоминается в современных исследованиях, но в других регионах не собирается целенаправленно. На Алтае уникальная лексика пчеловодства собрана по специально разработанной программе. В данной статье анализируется профессиональная лексика пчеловодов Алтая в аспекте взаимоотношения языка и культуры, а также исследуется состав лексики пчеловодства с точки зрения системных связей.

Ключевые слова: язык и культура, лексика пчеловодства, парадигматические связи, терминологическая лексика, системные связи.

«Инвентарь» и др. Работая с языковым материалом, необходимо обосновать принципы выделения тематических и лексико-семантических групп. Так, под тематической группой мы понимаем, вслед за Ф.П. Филиным, объединения слов, основывающиеся на классификации самих предметов и явлений, а под лексико-семантической группой - объединения слов, основывающиеся не только на классификации самих предметов и явлений, но и на семантической соотнесенности всех слов, входящих в нее [2, с. 527-528].

Терминологическое, тематическое (понятийное) поле вызывает массу интерпретаций в современной лингвистике, среди которых встречаются как определения по свойствам, так определения по внутренней организации и др. Ю.Д. Апресян приходит в выводу, что «словарь языка не является хаотическим нагромождением единиц, он распадается на некоторое число полей, объединяющих слова на основе их семантической общности» [3, с.52], а Б.Ю. Городецкий определяет семантическое поле как «совокупность семантических единиц, имеющих фиксированное сходство в каком - нибудь семантическом слое и связанных специфическими семантическими отношениями». [4, с.173] К наиболее общим типам корреляций между 
словами в рамках семантического поля относится синонимия: группа синонимических корреляций включает в себя отношения, основанные на полном или частичном совпадении словесных означаемых (многозначные слова рассматриваются в каком-то одном из узуальных значений); гипонимия - корреляции, называемые также родо-видовыми, связывают слово, обозначающее общее родовое понятие со словами, обозначающими частное подразделение этого понятия. Антонимия - группа корреляций, связывающих слова, выражающие в том или ином отношении противоположные понятия (комплиментарная антонимия - отношения дополнительности, которые характеризуют пару слов, когда отрицание того, что обозначает одно из них, влечет утверждение другого; векторная антонимия - разнонаправленные, действия. Контрарная антонимия - в значение входит указание на противоположные зоны шкалы.).

В целом, парадигматические отношения в лексике выделяются двух типов: внутрисловные (внутрилексемные) и междусловные (межлексемные), при этом к междусловным отношениям относятся омонимия, антонимия, синонимия, а внутрисловные отношения (варьирование слова и лексический вариант слова как единица такого варьирования) - полисемия, метафоризация, метонимический перенос.

Общие типы семантических корреляций выделяются и в лексике пчеловодства в русских говорах Алтая, так как положение о лексике как о системно организованном целом, естественно, должно быть применимо не только к литературному языку, но и к говорам [5, с.6]. Именно при изучении говоров деление лексики на тематические группы позволяет «наблюдать полные синонимические (или соответственные ряды)» [6, c.28].

Изучаемая нами лексика пчеловодства носит терминологический характер, так как обозначает понятия специальной области знания и специфической деятельности. Этот лексический пласт демонстрирует, что встречающиеся в реальном терминоупотреблении синонимы и многозначные термины отражают конкретные факты функционирования терминов, а не природу специальных слов. При этом вступает в силу природа общеязыкового знака, в результате чего термин становится выразителем разных содержаний (особенно, если в роли терминов выступают слова общелитературного употребления). В лексике пчеловодства на Алтае оказалось возможным выявить два и более оттенка значения слова, благодаря широким контекстам - записям живой речи алтайских пчеловодов.

В составе специальной лексики (в терминологии в широком понимании) также выделяются отраслевые терминосистемы, организация которых основана не на языковом принципе, а на предметно - логических связях соответствующих понятий, отражающих структуру изучаемого данной областью знания объекта. Основанием классификации лексики пчеловодства Алтая правомерно считать этапы технологического процесса производства продуктов пчеловодства.

Сравнивая такие лексические единицы, как слово и термин, по их отношению к внеязыковой действительности, по отношению к тому, что они называют, можно обнаружить двойственную природу значения слова: слово одновременно является знаком реалии и единицей языка, оно обозначает что-то вне языка и в то же время связано определенными отношениями с другими элементами языка. Терминология пчеловодства, записанная на Алтае, несомненно, обнаруживает системный характер лексики, с множеством структурно - семантических связей.

Для получения высоких сборов меда, воска и обеспечения быстрого роста пасеки пчеловоды соблюдают строгую последовательность действий - этапов в организации пчеловодного хозяйства. Традиционно началом подготовки к работе пасеки считается выбор места под пчельник, далее подбирается, в зависимости от главного направления хозяйственной деятельности пасеки, необходимый инвентарь, устанавливаются соответствующие поставленным задачам ульи, а затем, при тщательном изучении климатических условий региона, в ульи заселяются наиболее подходящие породы пчел. Особое значение в жизни пчелиной семьи имеют следующие этапы: развитие и размножение, главная роль в котором принадлежит пчелиной матке, а также роение пчел. Соблюдение всех правил в организации пчеловодного хозяйства способствует обильному медосбору, считающемуся самым главным этапом в технологическом процессе получения продуктов пчеловодства. Здесь важно правильно различать виды мёда, собранного пчелами во время медосбора. Когда заканчивается медосборный сезон, начинается самый ответственный и трудный период в жизни пчел, завершающий годовой цикл работ на пасеке, - зимовка.

Тематическая классификация терминов пчеловодства на Алтае построена нами на основании представленных выше этапов организации пчеловодного хозяйства. Таким образом, выстраивается целая система семантических полей, формирование каждого из которых осуществляется в два приема: сначала весь исходный список терминов пчеловодства на Алтае разбивается на поля, выделенные в соответствии с последовательными технологическими этапами производства продуктов пчеловодства (происходит движение к словарю семантических полей), а далее 
анализируется каждое поле (субполе) в отдельности: упорядочивается его внутренний состав, устанавливаются взаимоотношения лексических единиц.

\section{Выбор места под пчельник. Разновидности пасек}

Опытные пчеловоды утверждают, что «хорошая подготовка к сезону дает возможность пчеловоду ... вовремя выполнять все работы на пасеке» [7, с. 42]. Таким образом, залог успеха - именно качественно выполненные подготовительные работы, среди которых первым и немаловажным этапом является выбор места под пчельник (пасеку). Пасекой (пчельником) традиционно называется «место стоянки ульев с пчелами» [8, с. 118]. Алтайские пчеловоды с. Поспелиха подчеркивают, что на месте, выбранном под пчельник, не должно быть высоких деревьев и зарослей кустарников, потому что «высокие деревья затеняют ульи», это непременно должно быть «солнечное место, чтобы его никак не обдувал северный ветер, так как пчелы его, холодный, не любят. Ульи летками ставят на восток, бывает, на юг, но не у нас. Место должно быть сухое, не в ложбине, желательно на горочке весной или в начале лета. Лучше в лесу, там иветет акачия, а потом переносить в поле, там подсолнечник, гречиха, эспариет - где больше медоносов» (Егорьевский район Алтайского края).

Данные микрополя «Выбор места под пчельник» и «Разновидности пасек» репрезентируют следующие слова и словосочетания, зафиксированные в живой речи алтайских пчеловодов: горячий туман, кочёвная па́сека и кочевая пасека, пасек, пасека, пасечник, па́стик, пастика, пчеловодство и пщеловодство, пчельник и пщельник, стационарная пасека, точок.

Парадигматика анализируемых субполей представлена синонимическими (передвижные, кочевые, кочевные - «пасеки, которые перемещают для большего взятка»; точо́к, пщельник - «место, где расположены ульи»), антонимическими (стационарная пасека - передвижная, кочевая, кочевная пасека) и вариантными отношениями (пасека - пасек, пастика - пастик лексико - грамматические варианты; пасека - пастика - лексико-фонетические варианты). Можно выделить также гипонимические отношения: значение слова па́сека шире значения слов точок, пчельник - «место, где расположены ульи» и включает в себя это значение (пщельник, точок - «расчищенная площадка, на которой расставлены ульи», а пасека - «расчищенная площадка, на которой расставлены ульи, весь инвентарь, пчёлы, продукция»). Согласно теории семантического поля, антонимические отношения близки к логическим контрарным, они шире, чем обыкновенная лексическая антонимия, потому что те значения, которые в общепринятом понимании не являются антонимами, в рамках семантического поля ими становятся, поскольку «включаются в одно и то же множество, носящее родовое наименование (суперординату) [6, с.110]. В поле, выстроенном для группы «Выбор места под пчельник», противопоставленность обусловлена общелексической антонимией компонентов: стационарная пасека - та, которая стоит на постоянном месте, а передвижная, кочевая, кочевная па́сека - та, которая меняет место расположения в зависимости от условий. Таким образом, стационарная пасека означает отсутствие передвижно́й, то есть исключает возможность передвижения. И поскольку антонимы в лексике находятся в отношении исключающей дизъюнкции (кочевая пасека не может быть одновременно стационарной так же, как стационарная, - передвижной), «то выявление антонимических оппозиций в семантическом поле есть процесс превращения неисключающей дизъюнкции в исключающую». Этот процесс осуществляется путём включения значений в одно родовое имя, путём установления границ самого противопоставления, поэтому утверждается, что поле индуцирует антонимы [6, c.110].

Основные содержательные компоненты значений сравниваемых нами слов пасека, пастик, пасек или кочевые, кочевные или точок, пщельник одинаковы, то есть значение слова па́сек «пасека», которое проявлено в «Словаре русских говоров Алтая» в контексте: «Пчелиный пасек, там пчелы живут (Зал.) Далеко лазили за ягодами? - Мы в пасек совхозный» (Бийск., Луг.) [9, т.3, ч.2, с. 20] сравнивается и совпадает с другим значением пастик, пастика - «то же, что пасек», в контексте: «Батя пастик держал. Батя за пастиком ходил» (Тог.) [9, т.3, ч.2, с. 21] и «Мы бы сладкова не видали, если бы не пастика» (Тог.) [9, т.3, ч.2, с. 21]. Таким образом, эти значения состоят в нулевой оппозиции по отношению друг к другу, у данных синонимов основные компоненты тождественны, а различаются только некоторыми оттенками значений, проявленными в контекстах из записей живой речи алтайских пчеловодов. В материале обнаружена также оппозиция строгого включения, когда значение «пасека» выступает как родовое по отношению к видовому значению сочетаний слов стационарная пасека, передвижная, кочевая, кочевная пасека, то есть наблюдается привативная оппозиция, где стационарная пасека, передвижная, кочевая, кочевная пасека - гипонимы по отношению к вариантному ряду пасека, пастик, пастика, пасек«пасека». Анализ данной оппозиции позволяет установить логическую структуру семантического поля, базу которого составляют синонимические отношения, содержащие гипонимы.

Таким образом, парадигматика анализируемых субполей представлена гипонимическими, синонимиче- 
скими, антонимическими и вариантными отношениями. Тождество значений выявлено как в рамках одного пчеловодного района, так и в селах, находящихся на большом расстоянии друг от друга.

\section{ЛИТЕРАТУРА}

1. Покровский, М.М. Избранные работы по языкознанию / Акад. наук СССР. Отд-ние литературы и языка. - Москва : Изд-во Акад. наук СССР, 1959. С. 82.

2. Филин, Ф.П. 0 лексико - семантических группах слов / Ф.П. Филин // Езиковедски изследования в чест на акад. Ст. Младенов, - София, 1957. - С. 523 - 538.

3. Апресян Ю.Д. Лексическая семантика. - М.: Наука, 1974.С.52.

4. Городецкий, Б.Ю. К проблеме семантической типологиии / Б.Ю. Городецкий. - М.: Изд. Моск. ун-та, 1969. С.173.

5. Ильинская, Н.Г. К проблеме системных отношений в лексике / Н.Г. Ильинская. - М.: Диалог МГУ, 1998. С.6.

6. Караулов, Ю.Н. Общая и русская идеография / Ю.Н. Караулов. - М.: Наука, 1976. С.28.

7. Кашковский, В.Г. Кемеровская система ухода за пчелами / В.Г. Кашковский. - Кемерово: Кем. кн-е изд-во, 1968. С.42.

8. Коптев, В.С. Карманная книга пчеловода / В.С. Коптев. - Новосибирск: Зап.-Сиб. кн. изд, 1966. С.118.

9. Словарь русских говоров Алтая: В 4-х т. - Барнаул: Изд-во Алт. ун-та, 1993 - 1998.

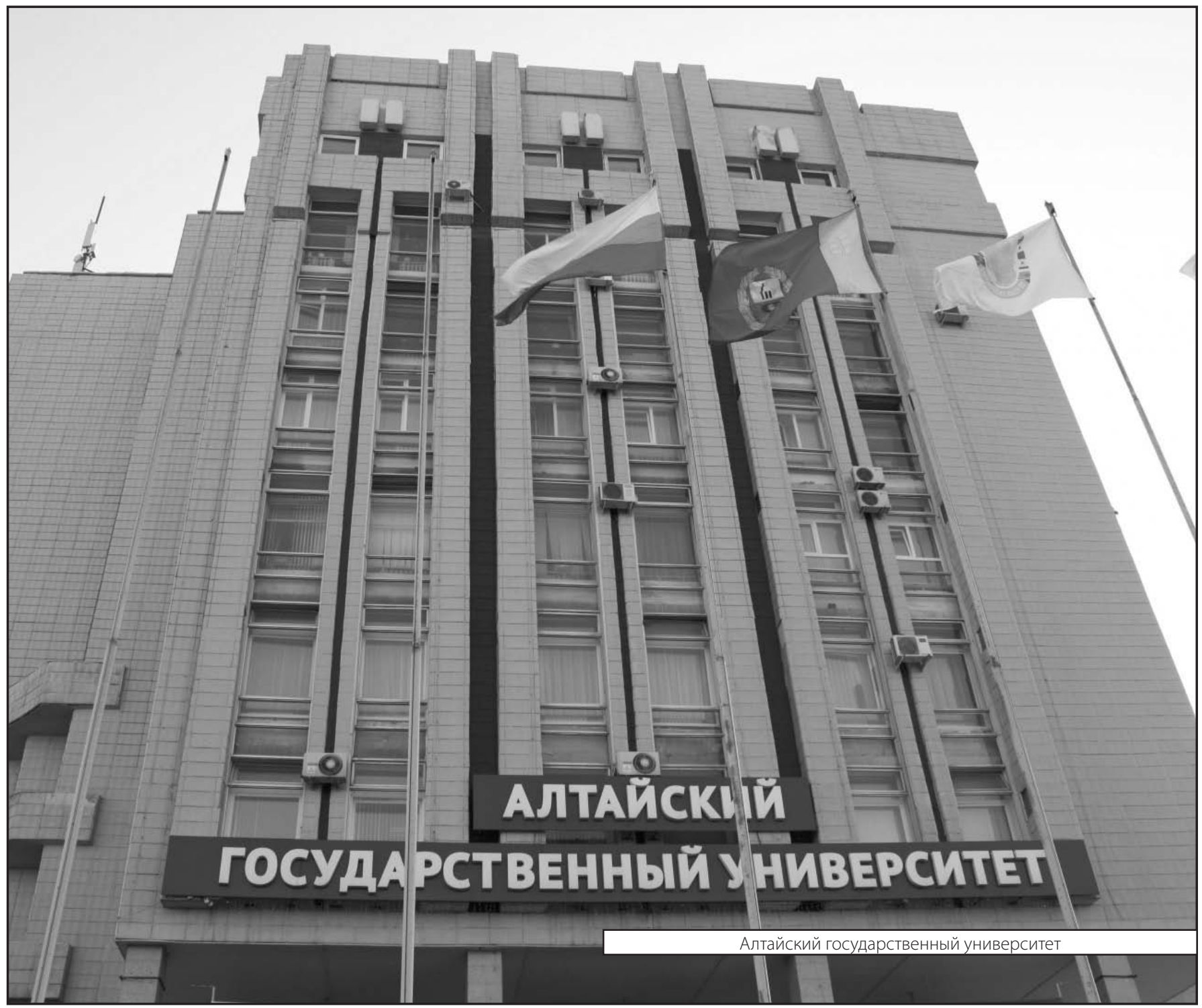

